\title{
Risk Preferences, Rationality of Choices, and Willingness to Pay for Preventive Medicine in Patients with Graves' Thyrotoxicosis
}

\author{
Naoya Emoto (D) ${ }^{1-3}$ \\ Mikiko Okazaki-Hada (D) \\ Yuji Yamaguchi ${ }^{1}$ \\ Fumitaka Okajima (iD) ${ }^{1,2}$ \\ Rei Goto ${ }^{4}$ \\ Hitoshi Sugihara' \\ 'Department of Endocrinology, Diabetes \\ and Metabolism, Graduate School of \\ Medicine, Nippon Medical School, Tokyo, \\ Japan; ${ }^{2}$ Department of Diabetes, \\ Endocrinology and Metabolism, Nippon \\ Medical School Chiba Hokusoh Hospital, \\ Chiba, Japan; ${ }^{3}$ Diabetes \& Thyroid Clinic, \\ Sakura Chuo Hospital, Chiba, Japan; \\ ${ }^{4}$ Graduate School of Business \\ Administration, Keio University, Tokyo, \\ Japan
}

Purpose: Patients with thyrotoxicosis show neuropsychological changes, and these may damage the quality of informed consent in clinical practice. Therefore, we examined patients' real-life preferences to assess whether change in risk preferences was dependent on thyroid function state.

Patients and Methods: The participants were 86 patients who were newly diagnosed with Graves' thyrotoxicosis between 1 January and 31 December 2018 (group A), and an additional 33 euthyroid patients diagnosed before 2018 (group B). In a survey conducted via a questionnaire based on the concept of behavioral economics, we sought to determine risk preferences, rationality of choices, and other relevant factors. An identical second survey was completed 6-12 months later by 36 patients in group A after their thyroid functions had been normalized by treatment, and by 11 euthyroid patients in group B. We performed paired analysis of the first and second surveys in 32 patients of group A and single regression analysis of a total of 140 surveys obtained from 119 patients by combining the first and second surveys of groups A and B with serum level of FT3 as an independent variable. Results: The paired analysis indicated that there was no significant difference in any survey item. The single regression analysis revealed that willingness-to-pay (WTP) for preventive medicine and monthly average out-of-pocket (OOP) expenditure on medical care were both significantly positively associated with serum level of FT3. Patients in the hyperthyroid state tend to have high WTP for preventive medicine, which may be accelerated by the anchoring effect of OOP expenditure.

Conclusion: Almost all risk preferences of patients with Graves' disease are constant, rational, and reproducible in the hyperthyroid and euthyroid states. However, medical professionals should be aware that the willingness of patients with thyrotoxicosis to pay for medical costs may change after the normalization of thyroid function.

Keywords: informed consent, behavioral economics, out-of-pocket expenditure, anchoring effects

\section{Introduction}

It has been reported that patients with thyrotoxicosis show mental disturbances and behavioral changes that can include manic, depressive, or cognitive decrements. ${ }^{1,2}$ These patients sometimes have difficulty in concentrating and problems with memory or decision making. ${ }^{3-6}$ These mental symptoms usually disappear after reaching euthyroidism. ${ }^{7,8}$ Although the biological mechanism for these symptoms remains unknown, recent studies using functional neuroimaging techniques of positron emission tomography (PET) and single photon emission computed
Correspondence: Naoya Emoto Diabetes \& Thyroid Clinic, Sakura Chuo Hospital, 20-4, Sakaecho, Sakura City, Chiba, 285-0014, Japan

Tel $+8|-43-486-| 3||$

Fax $+8|-43-486-13| 4$

Email emotonaoya1954@gmail.com 
tomography (SPECT) have revealed that excessive thyroid hormone induces abnormal metabolism in the limbic system and frontal cortex. ${ }^{9-11}$

Informed consent for clinical treatment has evolved to become vitally important in modern medical practice. In general, informed consent requires patients to have the capacity to make relevant decisions in an autonomous and rational way, ${ }^{12}$ in consideration of the specific risks and benefits. In patients who have mental disorders, special care should be taken to recognize possible disabilities in decision making when processing informed consent. ${ }^{13}$ Even without overt mental disturbance, however, it may be questionable whether patients with Graves' thyrotoxicosis are capable of making the reasonable decisions that the treating physicians would expect. If thyroid function state has a marked effect on patient preferences, then medical professionals should consider having a supporting decision-maker for the patient. Therefore, clarifying the risk preferences of patients with Graves' thyrotoxicosis seems critical for achieving high-quality informed consent.

The present study aimed to examine the risk preferences of patients with Graves' disease in terms of whether their risk preferences were constant or changed depending on thyroid function state. We have previously investigated risk preferences in a survey comprising real-life risk preference questions designed based on the concept of behavioral economics. ${ }^{14-16}$ In these studies, we demonstrated that irrational risk-seeking choices of patients with diabetes contributed to the progression of diabetic complications. We applied the same survey to patients with Graves' thyrotoxicosis and compared the results with those in the euthyroid state.

\section{Patients and Methods}

All 86 patients who were diagnosed with Graves' thyrotoxicosis between 1 January and 31 December 2018 (group A) were consecutively recruited to participate in a survey at the outpatient clinic of the Department of Diabetes, Endocrinology and Metabolism, Nippon Medical School Chiba Hokusoh Hospital, Chiba, Japan. The diagnosis of Graves' disease was based on hyperthyroxinemia, $>1 \%$ of the Tc-99m pertechnetate thyroid uptake with bilateral diffuse scintigraphy and a positive thyroid stimulating hormone (TSH)-binding inhibitory immunoglobulin (TBII) or thyroid stimulating antibody (TSAb). ${ }^{17}$ Also recruited to participate in the survey were an additional 33 patients with Graves' disease who had been diagnosed prior to 2018 and had been in euthyroid state for at least one year previously (group B). The exclusion criteria were consciousness disturbance (confusion, delirium, lethargy, stupor, and coma), overt psychiatric disorder (patients who required consulting with psychiatrists), mental retardation, dementia, inability to understand Japanese language, and those who declined the recruitment request. In addition to the take-home survey, explanation sheet, and consent form, each survey participant was given book coupons worth $¥ 500$ (equivalent to \$5 USD) as token remuneration. The participants were asked to examine the explanation sheets and consent forms at home, complete the survey forms, and return them along with the signed informed consent form by postal mail. Of the 119 participants, 54 patients in group A and 11 patients in group B were recruited to participate in a second survey (flow chart in Supplemental Figure S1). The interval between the first and second surveys was 612 months, and all patients were in euthyroid state with methimazole, propylthiouracil $(\mathrm{n}=3)$, or iodine (iodine only, $\mathrm{n}=3$; methimazole with iodine, $\mathrm{n}=2$ ) at the time of the second survey. The duration in euthyroid state in group A patients at the second survey was $112 \pm 91$ days (mean \pm $\mathrm{SD})$. We used the same questionnaire for both surveys, as described previously, ${ }^{14-16}$ as a modified version of the Japan Household Survey on Consumer Preference and Satisfaction by the Institute of Social and Economic Research, Osaka University, Osaka, Japan (https://www. iser.osaka-u.ac.jp/survey_data/top_eng.html). The reliability and validity of the questionnaire have been established in the general population, ${ }^{18}$ including those with obesity ${ }^{19}$ and smokers. ${ }^{20}$ The survey items sought to determine patients' risk preferences as well as relevant factors such as personal socioeconomic status, mind and mood, and propensity (Supplemental Table S1, the Japanese version is shown in Supplemental Figure S2). We examined rationality in answers to hypothetical lottery and insurance policy questions (Q12 and Q13). Irrational answers were defined as violations of two axioms of the expected utility theory: completeness and transitivity, as described in our previous report. ${ }^{16}$ Serum levels of free thyroxine (FT4), free triiodothyronine (FT3), and thyrotropin (TSH) were determined at the time of survey recruitment by microparticle enzyme immunoassay using an automated Abbott AxSYM system (Abbott, Tokyo, Japan). TBII and TSAb were measured by the DYNOtest TRAb Human kit "Yamasa" and the TSAb kit YAMASA EIA (Yamasa, Chiba, Japan). This study was conducted in accordance with the principles of the Declaration of Helsinki. The 
study protocol, including the consent form with confidentiality clause, was approved by the Internal Review Board of the Ethics Committee of Nippon Medical School.

\section{Statistical Analysis}

Statistical analyses were performed using JMP ${ }^{\circledR} 13$ (SAS Institute Japan, Tokyo, Japan). Paired analysis of differences between the results of the first and the second surveys were assessed with Student's paired $t$-test for continuous variables and McNemar-Bowker test for nominal scales. Using serum level of FT3 as an independent variable, single regression analysis was performed for the answers to Q1-Q5 and Q8-13 as dependent variables in which all answers were treated as continuous variables. Single logistic regression analysis was performed for the answers to Q6 and Q7 (procrastination) and Q12 and Q13 (rationality), with serum level of FT3 as an independent variable. In multiple regression analysis, variance inflation factor was used to detect multicollinearity. Statistical significance was set at $\mathrm{p}<0.05$.

\section{Results}

Table 1 lists the participants' characteristics. The first survey was completed by 65 patients in group A (76\%) and 28 patients in group B (85\%), and the second survey was completed by 36 patients in group A (67\%), after their thyroid functions had been normalized by treatment, and 11 patients in group B (100\%). Table 2 shows paired analysis of differences between the first and the second survey in patients in group A who were hyperthyroid at the first survey and euthyroid at the second survey. A total of 32 paired samples were obtained and analyzed with paired $t$-tests for continuous variables and McNemar-Bowker tests for nominal scales. The paired test found no significant difference in responses to all survey items between the first and the second surveys.

Due to the diverse severities of thyrotoxicosis, we considered that dichotomization as hyperthyroid or euthyroid could risk loss of critical information and analytic power. Therefore, we analyzed the data using serum level of FT3 as a marker of thyroid function. Table 3 shows the single regression analysis of each survey item, using serum level of FT3 as an independent variable. A total of 140 surveys (combined first and second surveys of groups A and B) were analyzed, obtained from 119 patients. There was no association of the answers to risk preference items (Q1, Q2, Q10-13) with serum level of FT3. In addition, FT3 level did not influence survey items related to mind and mood: feeling rushed (Q3), sleep deprivation (Q4, Q5), estimated propensity to procrastinate (Q6, Q7), accept medical uncertainty (Q8), and make rational choices $(\mathrm{Q} 12, \mathrm{Q} 13)$. In the items regarding preferences, willingness-to-pay (WTP) for a medicine that could reduce cardiovascular disease (CVD) risk (WTPcvr) (Q11) was the only factor significantly associated with serum level of FT3 $(p=0.0052)$. Figure 1 shows the linear fit of WTPcvr prices according to FT3 level $\left(\mathrm{R}^{2}=0.058\right)$. WTPcvr increased as FT3 level increased; however, among the relevant factors, out-ofpocket (OOP) monthly expenditure on medical care (OOPmed) (Q9) was also positively associated with FT3 level (Figure 2) $\left(\mathrm{R}^{2}=0.0508, \mathrm{p}=0.0079\right)$. OOPmed was also associated with WTPcvr (Figure 3$)\left(\mathrm{R}^{2}=0.0840, \mathrm{p}=\right.$ 0.0008). The same results were obtained when we

Table I Clinical Characteristics of the Participants

\begin{tabular}{|c|c|c|c|}
\hline \multirow[b]{2}{*}{ Thyroid Status at Initial Survey Recruitment } & Group A & Group B & \multirow[t]{2}{*}{ p value } \\
\hline & Hyperthyroid & Euthyroid & \\
\hline n (male:female) & $86(16: 70)$ & $33(3: 30)$ & \\
\hline Treatment duration & Within I month & $\mathrm{I}-20$ years & $<0.001$ \\
\hline Age $(y)$ & $47.2 \pm 14.2$ & $51.7 \pm 16.8$ & 0.184 \\
\hline $\mathrm{TSH}(\mu \mathrm{IU} / \mathrm{mL})(0.35-4.94)^{\mathrm{a}}$ & $<0.001$ & $1.69 \pm 1.16$ & $<0.001$ \\
\hline FT3 $(\mathrm{pg} / \mathrm{mL})(I .7 I-3.7 I)^{\mathrm{a}}$ & $5.73 \pm 4.48$ & $2.52 \pm 0.31$ & $<0.001$ \\
\hline FT4 (ng/dL) (0.70-I.48) ${ }^{\mathrm{a}}$ & $1.76 \pm 0.83$ & $0.95 \pm 0.12$ & $<0.001$ \\
\hline First survey returned, $\mathrm{n}(\%)$ & $65(76)$ & $28(85)$ & 0.260 \\
\hline Second survey recruitment $\mathrm{n}$ (male:female) & $54(10: 44)$ & II $(I: 10)$ & 0.419 \\
\hline Second survey returned, $\mathrm{n}(\%)$ & $36(67)$ & II (I00) & 0.005 \\
\hline
\end{tabular}

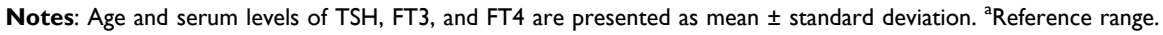


Table 2 Paired Analysis of Differences Between the First and the Second Survey in Group A Patients (Hyperthyroid at the First Survey and Euthyroid at the Second Survey)

\begin{tabular}{|c|c|c|c|c|}
\hline Variable & First & Second & t or Chi-Square & p value \\
\hline Age $(y)$ & $46.0 \pm 14.2$ & $46.7 \pm 14.2$ & & \\
\hline Survey returned, ${ }^{\mathrm{a}} \mathrm{n}(\%)$ & $39(75)$ & $36(69)$ & 0.818 & 0.366 \\
\hline Body mass index $\left(\mathrm{kg} / \mathrm{m}^{2}\right)$ & $21.5 \pm 3.1$ & $22.1 \pm 3.0$ & 4.77 & $<0.001$ \\
\hline $\mathrm{TSH}(\mu \mathrm{IU} / \mathrm{mL})(0.35-4.94)^{\mathrm{b}}$ & $<0.001^{d}$ & $1.85 \pm 1.28$ & 10.4 & $<0.001$ \\
\hline FT3 $(\mathrm{pg} / \mathrm{mL})(\mathrm{I} .7 \mathrm{I}-3.7 \mathrm{I})^{\mathrm{b}}$ & $6.03 \pm 4.76$ & $2.39 \pm 0.31$ & -5.50 & $<0.001$ \\
\hline $\mathrm{FT} 4$ (ng/dL) $(0.70-\mathrm{I} .48)^{\mathrm{b}}$ & $1.79 \pm 0.86$ & $0.92 \pm 0.15$ & -6.83 & $<0.001$ \\
\hline QI General risk loving, weather & $50.5 \pm 21.6$ & $50.3 \pm 19.5$ & -0.425 & 0.681 \\
\hline Q2 General risk averse, travel & $22.9 \pm 11.0$ & $20.8 \pm 9.2$ & -1.02 & 0.317 \\
\hline Q3 Feeling rushed ${ }^{c}$ & $2.60 \pm 1.10$ & $2.50 \pm 1.20$ & -0.205 & 0.839 \\
\hline Q4 Sleeping hours & $6.29 \pm 1.04$ & $6.25 \pm 1.00$ & -0.636 & 0.530 \\
\hline Q5 Sleep deprivation ${ }^{\mathrm{c}}$ & $3.10 \pm 1.19$ & $3.14 \pm 1.22$ & 0.279 & 0.782 \\
\hline Q6 Procrastination, childhood ${ }^{\mathrm{a}}$ Early:Daily:End, n (\%) & $5: 8: 26(|3: 2|: 67)$ & $8: 8: 20(22: 22: 56)$ & 2.00 & 0.572 \\
\hline Q7 Procrastination, now ${ }^{\mathrm{a}}$ Early:Daily:End, n (\%) & $22: 9: 8(58: 23: 21)$ & 19:10:7 (53:28:19) & 1.20 & 0.753 \\
\hline Q8 Acceptance of medical uncertainty ${ }^{c}$ & $2.10 \pm 0.94$ & $1.94 \pm 0.83$ & -1.36 & 0.184 \\
\hline Q9 OOPmed (¥/month) & $8|4| \pm 6094$ & $6012 \pm 3726$ & -1.99 & 0.056 \\
\hline QI0 Subjective risk estimation for CVD (people/I00) & $30.7 \pm 25.1$ & $34.2 \pm 23.0$ & 0.781 & 0.441 \\
\hline QII WTPcvr (¥/month) & $8929 \pm 16,378$ & $7000 \pm 9789$ & -1.33 & 0.194 \\
\hline QI2 Lottery, risk taker, maximum price ( $¥)$ & $1327 \pm 215$ & $|286 \pm 22|$ & -0.576 & 0.569 \\
\hline Q12 Irrational response, $\mathrm{n}(\%)^{\mathrm{a}}$ & $5(12.8)$ & $5(13.9)$ & 0.333 & 0.564 \\
\hline QI3 Insurance, risk averse, maximum price $(¥)$ & $2810 \pm 2432$ & $4473 \pm 8536$ & 1.19 & 0.245 \\
\hline Q13 Irrational response, $\mathrm{n}(\%)^{\mathrm{a}}$ & $5(12.8)$ & $4(I I . I)$ & 0.000 & 1.000 \\
\hline
\end{tabular}

Notes: A total of 32 paired samples were analyzed. Data are presented as the number, $\%$, or mean \pm standard deviation. Paired $t$-tests were performed for continuous variables. ${ }^{a}$ For nominal scales, McNemar-Bowker tests were applied using chi-square test. ${ }^{b}$ Reference range. ${ }^{c}$ Ordinal scales were treated as continuous variables. ${ }^{\mathrm{d}} \mathrm{TSH}<$ $0.001(\mu \mathrm{IU} / \mathrm{mL})$ was calculated as zero.

Abbreviations: OOPmed, out-of-pocket average monthly expenditure on medical care; CVD, cardiovascular disease; WTPcvr, willingness-to-pay for a medicine that could reduce CVD risk.

analyzed data using serum levels of FT4 as a marker of thyroid function (Supplemental Figures S3 and $\underline{\mathrm{S}}$ ).

To clarify the relationship between average OOPmed, WTPcvr, and serum level of FT3, we performed multiple regression analysis using WTPcvr as a dependent variable (Table 4). In this analysis, we included subjective risk estimation for CVD (Q10) and economic status (Q17) as independent variables because it seems reasonable to assume that these factors might affect WTPcvr price. The results indicate that FT3 level and OOPmed were independently associated with WTPcvr. Subjective risk estimation (Q10) and economic status (Q17) were not significantly associated with
WTPcvr. Multiple regression that allowed for correlation between the same individuals revealed the robust result of a statistically significant positive correlation between FT3 level and WTPcvr. No correlation between FT3 level and OOPmed was observed under this assumption.

\section{Discussion}

Patients' decision making in the process of informed consent is complicated by various factors, including mood state and personality traits. ${ }^{12,21}$ Although it has been previously suggested that patients with thyrotoxicosis showed impaired decision making, ${ }^{6}$ it is unclear whether their impaired 
Table 3 Single Regression Analysis of Survey Items Using Serum Level of FT3 as an Independent Variable

\begin{tabular}{|c|c|c|c|c|c|}
\hline Dependent Variable & n, \%, or Mean \pm SD & Estimate & Standard Error & $\begin{array}{l}\text { t Ratio or } \\
\text { Chi-Square }\end{array}$ & p value \\
\hline Surveys returned, ${ }^{\mathrm{a}, \mathrm{b}} \mathrm{n}(\%)$ & $140(76)$ & -0.064 & 0.063 & 1.01 & 0.315 \\
\hline QI General risk loving, weather & $50.8 \pm 20.3$ & 0.716 & 0.470 & 1.52 & 0.130 \\
\hline Q2 General risk averse, travel & $20.9 \pm 11.0$ & -0.015 & 0.258 & -0.060 & 0.954 \\
\hline Q3 Feeling rushed ${ }^{c}$ & $2.60 \pm 1.20$ & 0.013 & 0.029 & 0.740 & 0.642 \\
\hline Q4 Sleeping hours & $6.22 \pm 1.08$ & -0.011 & 0.025 & -0.420 & 0.676 \\
\hline Q5 Sleep deprivation ${ }^{\mathrm{C}}$ & $3.01 \pm 1.22$ & -0.019 & 0.029 & -0.670 & $0.50 \mathrm{I}$ \\
\hline $\begin{array}{l}\text { Q6 Procrastination, childhood }{ }^{\mathrm{b}} \text { Early:Daily:End, n (\%) } \\
\text { Early vs End } \\
\text { Daily vs End }\end{array}$ & $26: 31: 83(19: 22: 59)$ & $\begin{array}{l}-0.058 \\
-0.237\end{array}$ & $\begin{array}{l}0.070 \\
0.131\end{array}$ & $\begin{array}{l}0.690 \\
3.24\end{array}$ & $\begin{array}{l}0.407 \\
0.072\end{array}$ \\
\hline $\begin{array}{l}\text { Q7 Procrastination, now }{ }^{\mathrm{b}} \text { Early:Daily:End, n (\%) } \\
\text { Early vs End } \\
\text { Daily vs End }\end{array}$ & $80: 31: 29(57: 22: 21)$ & $\begin{array}{l}-0.034 \\
0.007\end{array}$ & $\begin{array}{l}0.058 \\
0.063\end{array}$ & $\begin{array}{l}0.440 \\
0.010\end{array}$ & $\begin{array}{l}0.509 \\
0.906\end{array}$ \\
\hline Q8 Acceptance of medical uncertainty ${ }^{c}$ & $2.06 \pm 0.88$ & -0.013 & 0.020 & -0.660 & 0.510 \\
\hline Q9 OOPmed (¥/month) & $7|89 \pm 627|$ & 385 & 143 & 2.70 & 0.008 \\
\hline QI0 Subjective risk estimation for CVD (people/I00) & $31.1 \pm 22.4$ & -0.624 & 0.522 & -1.20 & 0.234 \\
\hline QII WTPcvr (¥/month) & $7306 \pm 11,436$ & 741 & 261 & 2.84 & 0.005 \\
\hline Q।2 Lottery, risk taker, maximum price ( $¥)$ & $1095 \pm 1474$ & 24.6 & 34.4 & 0.710 & 0.476 \\
\hline QI2 Irrational response, $n(\%)^{b}$ & $20(14.3)$ & -0.009 & 0.069 & 0.020 & 0.895 \\
\hline QI3 Insurance, risk averse, maximum price ( $¥)$ & $4061 \pm 7512$ & 4.53 & 176 & 0.030 & 0.980 \\
\hline Q13 Irrational response, $\mathrm{n}(\%)^{\mathrm{b}}$ & $20(14.3)$ & -0.029 & 0.076 & 0.150 & 0.6945 \\
\hline
\end{tabular}

Notes: A total of 140 surveys (combined first and second surveys of groups A and B) obtained from II9 patients were analyzed. ${ }^{2}$ Survey return rate was analyzed as the serum FT3 levels obtained at recruitment. ${ }^{b}$ For the nominal scales, logistic regression analysis was performed with chi-square test. ${ }^{c}$ Ordinal scales were treated as continuous variables.

Abbreviations: OOPmed, out-of-pocket average monthly expenditure on medical care; CVD, cardiovascular disease; WTPcrr, willingness-to-pay for a medicine that could reduce CVD risk.

decision making has a serious impact on the quality of informed consent in clinical practice. The design of the survey questionnaire used in the present study (Table $\underline{\text { S1 }})^{14-16}$ was based on the theory of behavioral economics, which has emerged as a new concept for clarifying irrational human behavior. ${ }^{22}$ Some of the survey items were adopted from an existing survey on consumer preference (Japan Household Survey on Consumer Preferences and Satisfaction $^{19,20}$ ). It is more suitable to examine patients' preferences in real life, which are relevant to informed consent, than to use those estimated by instrumental assessment. The present results demonstrated that general risk preferences, those of mind and mood (estimated by the survey items feeling rushed and sleep deprivation), and propensity estimated for the items procrastination, acceptance of medical uncertainty, and rationality of choices in patients with Graves' disease in thyrotoxicosis were not significantly different from those in the euthyroid state, and were not associated with serum level of FT3. Regarding the paired analysis, the second survey was completed within one year after the first survey. This time interval might be too short for any difference to be detected, because it has been reported that some patients who achieve euthyroid function after treatment might still have neuropsychological problems. ${ }^{8,23}$ However, in terms of the quality of informed consent it is important that patients' decisions would not fluctuate over such a short period. Our results suggest that as long as their mental status is not seriously impaired, 


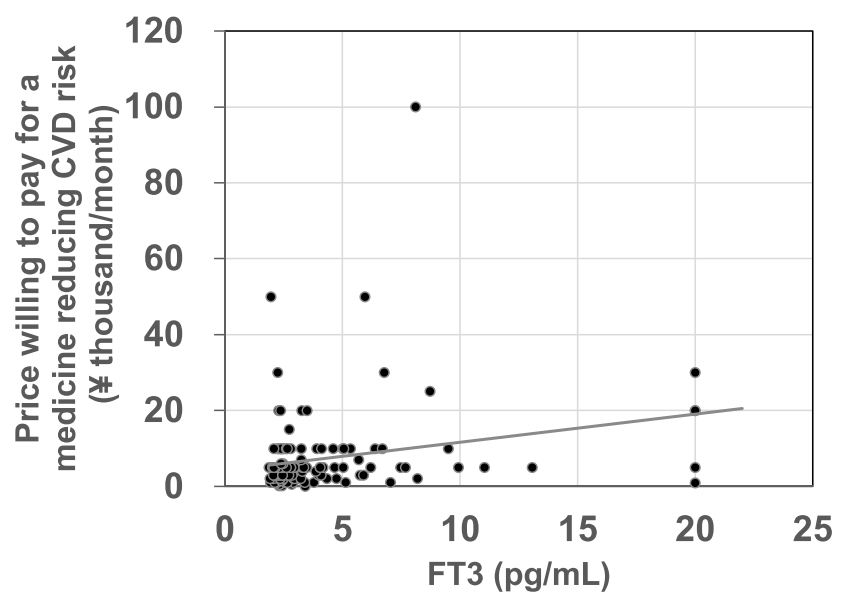

Figure I Linear fit of prices willing to pay for reducing CVD risk (QII) according to serum level of FT3. Of the 140 returned survey forms from a cumulative total of 184 surveys given to 119 patients, 7 surveys in 6 patients did not have answers for QII. A total of 133 answers in II3 patients were analyzed. Price willing to pay $(¥ /$ month $)=4219+741 \times \mathrm{FT} 3(\mathrm{pg} / \mathrm{mL}), \mathrm{R}^{2}=0.0580$. Analysis of variance; degree of freedom $=1$, sum of square $=1,000,897,112, F$ Ratio $=8.06, P=0.0052$.

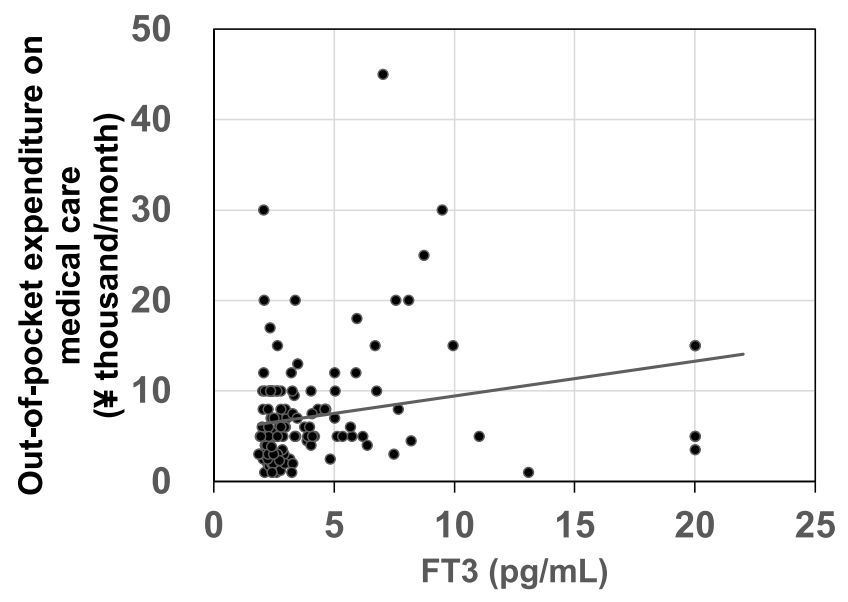

Figure 2 Linear fit of average out-of-pocket expenditure on medical care (Q9) according to serum level of FT3. Of the 140 returned survey forms from a cumulative total 184 surveys given to 119 patients, Q9 was not answered in two surveys. A total of 138 answers in 117 patients were analyzed. Out-of-pocket expenditure $(¥ / \mathrm{month})=5599+385 \times \mathrm{FT} 3(\mathrm{pg} / \mathrm{mL}), \mathrm{R}^{2}=0.0508$. Analysis of variance; degree of freedom $=I$, sum of square $=273,587,993, F$ Ratio $=7.28, p=0.0079$.

informed consent obtained from patients with Graves' thyrotoxicosis is robust and independent of thyroid function state.

The questionnaire items WTP for a lottery ticket (Q12) and for an insurance policy (Q13) were used to determine rationality. Irrational responses were defined as violations of two axioms of the expected utility theory: completeness and transitivity. ${ }^{24}$ These two axioms are familiar from consumer theory and are relevant to the process of informed consent. Gilboa speculated that the completeness axiom indicates that a certain choice has to be made and it rules out random

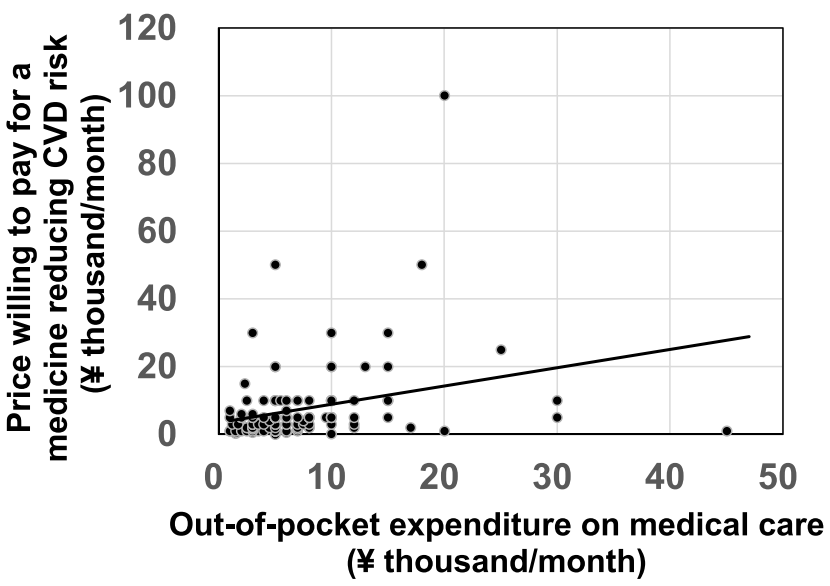

Figure 3 Linear fit of prices willing to pay for reducing CVD risk (QII) according to average out-of-pocket expenditure on medical care (Q9). A total of I3I answers in II I patients were analyzed. Price willing to pay ( $¥ /$ month $)=3484+0.540 \times$ outof-pocket expenditure ( $¥ /$ month), $R^{2}=0.0840$. Analysis of variance; degree of freedom $=1$, sum of square $=1,448,079,694, F$ Ratio $=11.84, p=0.0008$.

choices, and that transitivity (for any three outcomes A, B, and $\mathrm{C}$, a preference for $\mathrm{A}$ over $\mathrm{B}$ and a preference for $\mathrm{B}$ over $\mathrm{C}$ implies a preference for $\mathrm{A}$ over $\mathrm{C}$ ) is a mode of behavior that people would like to see themselves following. ${ }^{25}$ In other words, following transitivity means that people understand what kind of behavior is expected of them. Patients are expected to make decisions following the logic that physicians recognize to be a matter of course, but this is not always the case. We recently demonstrated that the incidence of violation of the two axioms was higher in patients with diabetes and retinopathy than in those without retinopathy. ${ }^{16}$ The present results indicated that incidence of violations of the axioms (irrational responses in Q12 and Q13) is not associated with thyroid function state, thus proving that the rationality in patients' decision making was constant and deliberate.

The only exception among the preference items was for WTPcvr when compared with serum level of FT3. WTPcvr was positively associated with serum level of FT3. This result is robust with the assumption of the error term. This finding suggests that thyrotoxicosis may induce patients to be generous with their money. Yuan et al reported that patients with hyperthyroidism preferred a high immediate gain but greater loss over time, estimated by Iowa Gambling Test. ${ }^{6}$ Although we did not examine the myopic time preferences in the present study, bold gambling bets in patients with thyrotoxicosis may be compatible with generosity with their money and higher levels of WTPcvr.

However, there is a possible contradiction to this interpretation. The result may be caused by "anchoring" of out- 
Table 4 Multiple Regression Analysis of Factors Associated with Price Willingness-to-Pay for a Medicine Reducing CVD Risk (WTPcrr) (QII)

\begin{tabular}{|c|c|c|c|c|c|}
\hline Independent Variable & Estimate & $\begin{array}{l}\text { Standard } \\
\text { Error }\end{array}$ & t Ratio & p value & VIF \\
\hline Age (y) & 24.6 & 68.0 & 0.360 & 0.718 & 1.02 \\
\hline FT3 $(\mathrm{pg} / \mathrm{mL})$ & 533 & 263 & 2.03 & 0.044 & 1.06 \\
\hline Q9 OOPmed (¥/month) & 0.435 & 0.160 & 2.72 & 0.008 & 1.08 \\
\hline QI0 Subjective risk estimation for CVD (people/I00) & -81.8 & 42.6 & -1.92 & 0.057 & 1.02 \\
\hline QI7 Economic status ${ }^{\mathrm{a}}$ & -162 & || $4 \mid$ & -0.140 & 0.887 & 1.02 \\
\hline
\end{tabular}

Notes: A total of 140 surveys obtained from 119 patients were analyzed. ${ }^{a}$ Ordinal scale was treated as a continuous variable.

Abbreviations: OOPmed, out-of-pocket average monthly expenditure on medical care; CVD, cardiovascular disease; VIF, variance inflation factor.

of-pocket monthly expenditure on medical care (OOPmed). Tversky and Kahneman described that in this phenomenon, people make estimates by starting with an initial value that is then adjusted to yield the final answer. $^{26}$ Different starting points yield different estimates, which are biased toward the initial values. Because anchors that have informational relevance to the task can lead to the anchoring effect, it is plausible that OOPmed may be the initial value of the estimation of WTPcvr. OOPmed is high during the first few months of medical care due to the number of tests that are required in a newly diagnosed patient, including blood tests for thyroid function and antibodies, nuclear thyroid scans, ultrasonography, and assessment of the cardiovascular system and other comorbidities. After the initiation of anti-thyroid medication, blood tests are then obtained every two to four weeks to monitor thyroid function and adverse effects until the euthyroid state is established. Additional assessments would be necessary in patients with comorbidities such as atrial fibrillation, heart failure, ophthalmopathy, glucose intolerance, or liver damage. Although this correlation is sensitive to the assumption of the error term, it may be possible that increased WTPcvr was the result of anchoring effects of OOPmed.

In consideration of other aspects of WTP for preventive medicine, it has been reported that spending for health care is closely related to household income worldwide. ${ }^{27-29} \mathrm{In}$ our previous study, we conducted exactly the same survey in patients with diabetes or stable endocrine or metabolic diseases. ${ }^{16}$ By way of comparison, we performed multiple regression analysis of the factors associated with WTPcvr from the data of that study. The results, listed in Supplemental Table S2, ${ }^{16}$ show that economic status was significantly associated with WTPcvr in patients with chronic diseases, but OOPmed was not. There was no anchoring effect of OOPmed on WTPcvr in patients with chronic diseases, whereas economic status had a strong impact. It should be noted that the association of serum level of FT3 with WTPcvr was statistically independent from OOPmed and economic status shown in Table 4. Thyrotoxicosis increased patients' WTPcvr independently of the anchoring effect. However, it has been suggested that this effect may be influenced by cognitive ability, personality traits, and mood, ${ }^{30}$ and that hyperthyroidism affects decision making, ${ }^{6}$ executive function, ${ }^{4}$ and $\operatorname{mood} .{ }^{2}$ Therefore, thyrotoxicosis may additionally increase WTPcvr by accelerating the anchoring effect of OOPmed.

One limitation of this study is that it included a small number of cases in a single facility in Japan. To avoid sampling bias, we recruited all patients who were newly diagnosed in 2018 and no patients were excluded by the recruitment criteria. At the time of recruitment, all of the patients agreed to participate, but the overall survey response rate was $76 \%$. Accordingly, we collected no data from $24 \%$ of the eligible patients. However, the response rate was $73.9 \%$ in patients with thyrotoxicosis and $78.2 \%$ in euthyroid state, which was not significantly different. Therefore, it may be plausible that the response rate did not affect the overall conclusions. Demographic factors may be another limitation, and could have influenced responses to survey items regarding risk preferences. Risk preferences relevant to informed consent should be investigated for every country, ethnic group, and socioeconomic status by a method that does not depend on patients' willingness to volunteer. Further studies will be necessary in this regard. Despite these limitations, the present study supports the robustness of informed consent obtained from patients with Graves' thyrotoxicosis.

In conclusion, the risk preferences of patients with Graves' disease are constant and reproducible in both the hyperthyroid and euthyroid states. Informed consent during thyrotoxicosis is reliable as long as the patient's mental status is not seriously impaired. However, patients in 
thyrotoxicosis may have higher levels of willingness to pay for medical costs than those in the euthyroid state, which may change after normalization of thyroid function. The findings of the present study suggest that investigations of disease-specific preference changes may be necessary for every disease.

\section{Data Sharing Statement}

The data that support the findings of this study are stored in the Department of Endocrinology, Diabetes and Metabolism, Graduate School of Medicine, Nippon Medical School, and are available from the corresponding author upon reasonable request.

\section{Ethics Approval and Informed Consent}

This study was conducted in accordance with the Declaration of Helsinki. The study was approved by the Internal Review Board of the Ethics Committee of Nippon Medical School Chiba Hokusoh Hospital (\#415). The study participants provided written informed consent for the study contents, purposes, protocols, data confidentiality and anonymity procedures, and publication. Freedom to discontinue the study at any stage was explained and agreed upon.

\section{Acknowledgments}

The authors would like to thank FORTE Science Communications for assistance with English language review.

\section{Author Contributions}

All authors made a significant contribution to the work reported, whether that is in the conception, study design, execution, acquisition of data, analysis and interpretation, or in all these areas; took part in drafting, revising or critically reviewing the article; gave final approval of the version to be published; have agreed on the journal to which the article has been submitted; and agree to be accountable for all aspects of the work.

\section{Funding}

This study was supported by a Grant-in-Aid for scientific research from the Japan Society for the Promotion of Science (KAKENHI) for Research Project \#17K08936 (FY 2017-2019).

\section{Disclosure}

The authors report no conflicts of interest.

\section{References}

1. Feldman AZ, Shrestha RT, Hennessey JV. Neuropsychiatric manifestations of thyroid disease. Endocrinol Metab Clin North Am. 2013;42 (3):453-476. doi:10.1016/j.ecl.2013.05.005

2. Samuels MH. Cognitive function in untreated hypothyroidism and hyperthyroidism. Curr Opin Endocrinol Diabetes Obes. 2008;15 (5):429-433. doi:10.1097/MED.0b013e32830eb84c

3. Trzepacz PT, McCue M, Klein I, Levey GS, Greenhouse J. A psychiatric and neuropsychological study of patients with untreated Graves' disease. Gen Hosp Psychiatry. 1988;10(1):49-55. doi:10.1016/0163-8343(88)90084-9

4. Yudiarto FL, Muliadi L, Moeljanto D, Hartono B. Neuropsychological findings in hyperthyroid patients. Acta Med Indones. 2006;38(1):6-10.

5. Yuan L, Tian Y, Zhang F, et al. Impairment of attention networks in patients with untreated hyperthyroidism. Neurosci Lett. 2014;574:26-30. doi:10.1016/j.neulet.2014.05.016

6. Yuan L, Tian Y, Zhang F, et al. Decision-making in patients with hyperthyroidism: a Neuropsychological Study. PLoS One. 2015;10 (6):e0129773. doi:10.1371/journal.pone.0129773

7. Vogel A, Elberling TV, Hørding M, et al. Affective symptoms and cognitive functions in the acute phase of Graves' thyrotoxicosis. Psychoneuroendocrinology. 2007;32(1):36-43. doi:10.1016/j. psyneuen.2006.09.012

8. Yuan L, Zhang Y, Luan D, et al. Reversible affective symptoms and attention executive control network impairment following thyroid function normalization in hyperthyroidism. Neuropsychiatr Dis Treat. 2019;15:3305-3312. doi:10.2147/NDT.S227386

9. Schreckenberger MF, Egle UT, Drecker S, et al. Positron emission tomography reveals correlations between brain metabolism and mood changes in hyperthyroidism. J Clin Endocrinol Metab. 2006;91 (12):4786-4791. doi:10.1210/jc.2006-0573

10. Miao Q, Zhang S, Guan YH, et al. Reversible changes in brain glucose metabolism following thyroid function normalization in hyperthyroidism. AJNR Am J Neuroradiol. 2011;32(6):1034-1042. doi:10.3174/ajnr.A2449

11. Pak K, Kim M, Kim K, Kim BH, Kim SJ, Kim IJ. Cerebral glucose metabolism and cerebral blood flow in thyroid dysfunction: an activation likelihood estimation meta-analysis. Sci Rep. 2020;10(1):1335. doi:10.1038/s41598-020-58255-5

12. Hall DE, Prochazka AV, Fink AS. Informed consent for clinical treatment. Cmaj. 2012;184(5):533-540. doi:10.1503/cmaj.112120

13. Scholten M, Gather J, Vollmann J. Equality in the informed consent process: competence to consent, substitute decision-making, and discrimination of persons with mental disorders. J Med Philos. 2021;46 (1):108-136. doi:10.1093/jmp/jhaa030

14. Emoto N, Okajima F, Sugihara H, Goto R. Behavioral economics survey of patients with type 1 and type 2 diabetes. Patient Prefer Adherence. 2015;9:649-658. doi:10.2147/PPA.S82022

15. Emoto N, Okajima F, Sugihara H, Goto R. A socioeconomic and behavioral survey of patients with difficult-to-control type 2 diabetes mellitus reveals an association between diabetic retinopathy and educational attainment. Patient Prefer Adherence. 2016;10:2151-2162. doi:10.2147/PPA.S116198

16. Emoto N, Soga A, Fukuda I, et al. Irrational responses to risk preference questionnaires by patients with diabetes with or without retinopathy and comparison with those without diabetes. Diabetes Metab Syndr Obes. 2020;13:4961-4971. doi:10.2147/DMSO.S283591

17. Kidokoro-Kunii Y, Emoto N, Cho K, Oikawa S. Analysis of the factors associated with Tc-99m pertechnetate uptake in thyrotoxicosis and graves' disease. J Nippon Med Sch. 2006;73(1):10-17. doi: $10.1272 /$ jnms. 73.10 
18. Watanapongvanich S, Binnagan P, Putthinun P, Khan MSR, Kadoya Y. Financial literacy and gambling behavior: evidence from Japan. J Gambl Stud. 2020;37(2):445.

19. Ikeda S, Kang MI, Ohtake F. Hyperbolic discounting, the sign effect, and the body mass index. J Health Econ. 2010;29(2):268-284 doi:10.1016/j.jhealeco.2010.01.002

20. Kang MI, Ikeda S. Time discounting and smoking behavior: evidence from a panel survey. Health Econ. 2014;23(12):1443-1464. doi: $10.1002 /$ hec. 2998

21. Lavelle-Jones C, Byrne DJ, Rice P, Cuschieri A. Factors affecting quality of informed consent. BMJ. 1993;306(6882):885-890. doi:10.1136/bmj.306.6882.885

22. Kahneman D. Thinking, Fast and Slow. New York: Farrar, Straus and Giroux; 2011.

23. Fahrenfort JJ, Wilterdink AM, van der Veen EA. Long-term residual complaints and psychosocial sequelae after remission of hyperthyroidism. Psychoneuroendocrinology. 2000;25(2):201-211. doi:10.1016/S0306-4530(99)00050-5

24. von Neumann J, Morgenstern O, Rubinstein A. Theory of Games and Economic Behavior. Princeton University Press; 1944.

25. Gilboa I. Theory of Decision Under Uncertainty. Cambridge: Cambridge University Press; 2009.
26. Tversky A, Kahneman D. Judgment under uncertainty: heuristics and biases. Science. 1974;185(4157):1124-1131. doi:10.1126/ science. 185.4157 .1124

27. Dickman SL, Woolhandler S, Bor J, McCormick D, Bor DH, Himmelstein DU. Health spending for low-, middle-, and highincome Americans, 1963-2012. Health Aff (Millwood). 2016;35 (7):1189-1196. doi:10.1377/hlthaff.2015.1024

28. Holbrook AM, Wang M, Lee M, et al. Cost-related medication nonadherence in Canada: a systematic review of prevalence, predictors, and clinical impact. Syst Rev. 2021;10(1):11. doi:10.1186/s13643020-01558-5

29. Tolla MT, Norheim OF, Verguet S, et al. Out-of-pocket expenditures for prevention and treatment of cardiovascular disease in general and specialised cardiac hospitals in Addis Ababa, Ethiopia: a Cross-Sectional Cohort Study. BMJ Glob Health. 2017;2(2): e000280. doi:10.1136/bmjgh-2016-000280

30. Furnham A, Boo HC. A literature review of the anchoring effect. J Socio Econ. 2011;40(1):35-42. doi:10.1016/j.socec.2010.10.008
Patient Preference and Adherence

\section{Publish your work in this journal}

Patient Preference and Adherence is an international, peer-reviewed, open access journal that focusing on the growing importance of patient preference and adherence throughout the therapeutic continuum. Patient satisfaction, acceptability, quality of life, compliance, persistence and their role in developing new therapeutic modalities and compounds to optimize clinical outcomes for existing disease

\section{Dovepress}

states are major areas of interest for the journal. This journal has been accepted for indexing on PubMed Central. The manuscript management system is completely online and includes a very quick and fair peer-review system, which is all easy to use. Visit http:// www.dovepress.com/testimonials.php to read real quotes from published authors. 